\title{
ANÁLISE DA INCURSÃO DO DIREITO INTERNACIONAL DOS DIREITOS HUMANOS AO TERRITÓRIO NORMATIVO DOS CONFLITOS ARMADOS: Um Enquadramento Para o Conflito Israel-Palestina em 2021
}

\author{
Sidney Guerra \\ Autor correspondente. Universidade do Grande Rio - Escola de Ciências Sociais Aplicadas. ACC I Shopping Unigranrio \\ - Jardim Vinte e Cinco de Agosto. Duque de Caxias/RJ, Brasil. CEP 25071-970. http://lattes.cnpq.br/6208018085527826. \\ http://orcid.org/0000-0002-5309-662X.sidneyguerra@terra.com.br \\ Ádria Fabricio \\ Universidade do Estado do Rio de Janeiro - Uerj. Rio de Janeiro/RJ, Brasil.
}

RESUMO

Este artigo tem como objetivo revisitar a inter-relação entre o Direito Internacional Humanitário (DIH) e o Direito Internacional dos Direitos Humanos (DIDH), em homenagem aos seus respectivos âmbitos normativos e com o objetivo de realizar uma análise de sua aplicação complementar ou suplementar, no sentido da conformação de uma ferramenta mais adequada para a proteção do ser humano em situações extremas, como ocorre durante os conflitos armados. Quanto ao método de abordagem considerando a base lógica da investigação, selecionou-se o método de procedimento hipotético-dedutivo, com abordagem qualitativa, bem como a técnica de pesquisa bibliográfica seguida pela análise do caso concreto Israel-Palestina, na medida em que a corroboração ou falsificação da hipótese principal será testada em casos de violações de direitos humanos no conflito supracitado. $O$ objetivo exploratório foi desenvolvido por meio da indicação de antinomias legais entre o DIDH e o DIH. Nesta investigação, concluiu-se que as posições mais adequadas para a proteção dos vulneráveis deveriam estar substancialmente alicerçadas nos fundamentos do DIDH quanto à ainda obscura área de transição entre as duas vertentes do Direito, visando à consolidação de uma compreensão doutrinária a fundamentar novas opiniões consultivas no futuro. Diante desse quadro, o cerne deste trabalho reside na compreensão da práxis para a aplicação complementar de ambos os aspectos nos conflitos armados, considerando não apenas o Direito Internacional dos Direitos Humanos como lex generalis, mas sua efetiva sobreposição em detrimento do Direito Internacional Humanitário quando é mais benéfico para a proteção humana.

Palavras-chave: Direito Internacional dos Direitos Humanos; Direito Internacional Humanitário; violações de direitos humanos; antinomia legal; conflito Israel-Palestina.

ANALYSIS OF THE INCURSION OF INTERNATIONAL HUMAN RIGHTS LAW TO THE NORMATIVE TERRITORY OF THE ARMED CONFLICTS: A FRAMEWORK FOR THE ISRAEL-PALESTINE CONFLICT IN 2021

\section{ABSTRACT}

This article aims to revisit the interrelationship between International Humanitarian Law (IHL) and International Human Rights Law (IHRL), in honour of their respective normative scopes and in order to carry out an analysis of their complementary or supplementary application, towards the construction of a more appropriate tool for the protection of human beings in extreme situations, as it occurs during armed conflicts. As for the method of approach concerning the logical basis of the investigation, the hypothetical-deductive procedure method was selected, with a qualitative approach, and a bibliographic research followed by a case analysis on the ongoing Israel-Palestine conflict in 2021, insofar as the corroboration or falsification of the main hypothesis will be tested to cases of human rights violations in the aforementioned conflict. The exploratory aim was developed through the understanding of indicating the legal antinomies between IHRL and IHL. In this investigation, it was concluded that the most appropriate positions for the protection of the vulnerable should be substantially grounded on IHRL fundamentals regarding the still obscure area of transition between the two areas, aiming at the consolidation of a doctrinal understanding to base new consultative opinions in the future. Given this framework, the core of this work lies in the understanding of the praxis for the complementary application of both aspects in armed conflicts, considering not only International Human Rights Law as lex generalis, but their effective overlap to the detriment of International Humanitarian Law, when it is most beneficial to human protection.

Keywords: International Human Rights Law; International Humanitarian Law; human rights violations; legal antinomy; Israel-Palestine conflict. 


\section{INTRODUÇÃO}

A relação de intensa proximidade entre o Direito Internacional Humanitário (DIH) e o Direito Internacional dos Direitos Humanos (DIDH), na seara teórica, enseja uma série de convergências fundamentais ao bom funcionamento da Proteção Internacional da Pessoa Humana em âmbito mundial. Com a finalidade primordial de proteger em todas as circunstâncias, a referida rede jurídica protetiva busca, inclusive, evitar que o indivíduo torne a sofrer, resguardando-o do sofrimento por intermédio, não só da repressão, como também da prevenção à violação de seus direitos.

Na prática, entretanto, as divergências no que concerne ao embate de regras e princípios aplicáveis aos casos concretos, bem como a interpretação utilizada para solucionar tais antinomias implicam, por vezes, consequências desastrosas ao objeto jurídico protegido, qual seja, a vida e a dignidade humanas.

Nesse contexto, o conflito Israel-Palestina surge como objeto ideal de pesquisa para este estudo, uma vez que nenhuma outra realidade advinda dos conflitos armados provoca tantas antinomias quanto a relação labiríntica entre a necessidade de subjugar as forças inimigas em direção ao objetivo militar da conquista - com uma ênfase na rendição - e a obrigação oposta de proteger a população do Estado ocupado, tanto por meio da obrigação negativa de não causar danos quanto mediante a obrigação positiva decorrente do governo do território ocupado e de sua população.

Aos aspectos mencionados, faz-se necessário agregar o que se entende, na perspectiva do presente estudo, como o principal problema de pesquisa: como harmonizar as normas do DIDH e do DIH - nos campos normativo, consultivo e jurisprudencial - nos casos de violações de direitos humanos perpetradas por representantes do Estado Ocupante contra a população do Estado ocupado, como no caso Israel-Palestina e o que este caso concreto nos ensina, particularmente quando analisamos o cenário de 2021.

Além disso, na iteração desta antinomia principal, as seguintes questões devem ser enfrentadas: se a harmonização não é possível porque as regras ou princípios se opõem, quais devem prevalecer? A análise da solução da antinomia deve ocorrer sob a regra de qual procedimento? Quais são as principais violações de direitos humanos e de normas humanitárias cometidas no conflito Israel-Palestina? Como diferenciar as violações dos direitos humanos e as violações do Direito Internacional Humanitário em conflitos armados como no caso em análise?

A intenção principal desta proposta é a busca pelo aprimoramento da Proteção Internacional da Pessoa Humana. Isto porque, permitir que uma norma supostamente efetiva - uma vez que na prática é deficiente, pois enseja arbitrariedades por parte do Estado sob o manto de seus princípios basilares - permaneça com jurisdição soberana, não só enseja a insegurança jurídica, como também gera uma sensação de proteção ilusória danosa, ainda mais quando presente no núcleo duro da proteção da pessoa humana.

Ao analisarmos o objeto de pesquisa referenciado, buscaremos compreender como se deve realizar a harmonização das normas concernentes ao Direito Internacional dos Direitos Humanos e ao Direito Internacional Humanitário - nas searas normativa, consultiva e jurisprudencial - em casos de violações de direitos humanos perpetradas por agentes estatais do 
Estado ocupante contra a população do Estado Ocupado, independentemente de resistência, nos Conflitos Armados Internacionais na modalidade ocupação militar, considerando o caso específico analisado. As normas de Direito Internacional Humanitário especificamente poderão ser referenciadas ao longo do texto como "normas humanitárias" para diferenciá-las das normas de direitos humanos.

Em um primeiro momento, esta pesquisa visa a conhecer brevemente as principais convergências e divergências que existem entre o Direito Internacional Humanitário e o Direito Internacional dos Direitos Humanos. Na sequência aprofundaremos a investigação para tratar das violações de direitos humanos perpetradas por agentes estatais do Estado Ocupante (Occupying Power) aos cidadãos do Estado Ocupado (Protecting Power) e do fenômeno dos conflitos assimétricos, bem como trataremos das especificidades da modalidade ocupação militar dos Conflitos Armados Internacionais e sua relação com o elemento fronteiriço do caso concreto escolhido.

No que diz respeito aos procedimentos metodológicos, estes serão a pesquisa bibliográfica e documental na primeira etapa descrita e a análise do estudo de caso na segunda. A terceira etapa consistirá em uma síntese dos resultados encontrados quando em contato com as variáveis preestabelecidas. A seleção das leituras para a pesquisa bibliográfica foi feita analiticamente e a análise documental com base nas fontes eleitas. Os trabalhos consultados para a construção teórica do artigo permanecem correlacionados ao final deste. A base de dados utilizada para a análise foi o sistema Rule of Law in Armed Conflicts Project (Rulac), ${ }^{1}$ da Geneva Academy, ${ }^{2}$ base que tem por objetivo monitorar os conflitos armados no mundo. Isto porque, a aplicação incorreta das normas de Direito Internacional Humanitário, com vícios de existência e validade, gera danos a todo o sistema normativo. Assim, com o intuito de oferecer uma classificação correta dos conflitos armados, as normas aplicáveis e as partes envolvidas no conflito, o sistema Rulac torna-se um parâmetro normativo para pesquisadores e outros profissionais que trabalhem com a área de Direito Internacional Humanitário.

The Rule of Law in Armed Conflicts project (Rulac) of the Geneva Academy of International Humanitarian Law and Human Rights is a unique online portal that identifies and classifies situations of armed conflict, provides information on the parties to these conflicts, and applicable international law. It aims to provide an independent and impartial classification of situations of armed conflict in the world based on open-source information in a format that is accessible to a wide audience, including non-lawyers and non-specialists in international humanitarian law. The Rulac project is a legal reference source for a broad audience interested in issues surrounding the classification of armed conflicts under in-

\footnotetext{
Projeto "Estado de Direito em Conflitos Armados" é um portal que objetiva identificar, monitorar e classificar as situações de violência armada no mundo e apresentar tais dados em formato acessível. É considerado globalmente uma fonte de referência legal de Direito Internacional Humanitário.

2 Universidade localizada em Genebra, na Suíça, a qual é considerada parâmetro mundial em estudos acerca do Direito Internacional Humanitário e dos Direitos Humanos.
} 
ternational humanitarian law, including legal experts, government officials, policy makers in international organizations or NGOs, humanitarian practitioners, and journalists who work on humanitarian or security issues, and academics ${ }^{3}$ (GENEVA ACADEMY, 2021).

\section{OS PARÂMETROS DE PROTEÇÃO DO DIREITO INTERNACIONAL HUMANITÁRIO E DO DIREITO INTERNACIONAL DOS DIREITOS HUMANOS}

Nesse sentido, analisaremos o enunciado (conjectura) a seguir, sendo que, caso a hipótese seja verdadeira, a conjectura também será: Podem as regras do Direito Internacional Humanitário e do Direito Internacional dos Direitos Humanos ser aplicadas em complementaridade em Conflitos Armados Internacionais na modalidade ocupação militar transfronteiriça como ocorre no caso concreto Israel-Palestina? Qual seria o mais aprimorado procedimento padrão para solucionar as antinomias decorrentes? Em seguida, a análise aplicará a teoria de corroboração e falsificação da seguinte hipótese: As regras do DIH e do DIDH podem ser aplicadas em complementaridade em Conflitos Armados Internacionais na modalidade ocupação militar transfronteiriça, e, particularmente, neste caso concreto Israel-Palestina atualizado para o contexto de 2021, as normas do DIDH devem ser sobrepostas às regras do DIH, a fim de realizar a proteção e prevenção de violações dos direitos humanos pelo Estado Ocupante (OTTO, 2012) contra a população do Estado Ocupado, restabelecendo a paridade, pelo menos legal, entre o Poder Ocupante e o Poder Protetor (PROVOST, 2004; KALSHOVEN; ZEGVELD, 2001).

A tese levantada para uma possível solução é que, de fato, a complementaridade entre os dois aspectos no contexto factual das ocupações militares é possível e indicada, para que a Proteção Internacional da Pessoa Humana se amplie nos conflitos armados. Isso deve ocorrer para que, em particular, o DIDH seja considerado não uma lex generalis (OBERLEITNER, 2015) - portanto, deixando de estar à mercê da legislação especial - além de atuar como parâmetro de proporcionalidade e de adequação ao Rule of Law humanitário internacional nesses casos, devendo inclusive prevalecer em situações particulares, conforme será demonstrado a seguir.

\subsection{Convergências e Divergências da Proteção Internacional da Pessoa Humana em Conflitos Armados}

Apesar das diversas perspectivas das teorias contratualistas, estas nos trazem como objetivo comum a análise da construção da ideia de Estado - criado para servir o ser humano - e o conceito uno de o ente jurídico estatal funcionar como o grande gerenciador das vontades humanas, regulamentando com o uso da ferramenta "Direito" a vida em sociedade, para que sua existência continue a ser possível. Por meio das normas, as quais passaram a constituir as

\footnotetext{
O projeto Estado de Direito em Conflitos Armados (RULAC) da Academia de Genebra de Direito Internacional Humanitário e Direitos Humanos é um portal on-line exclusivo que identifica e classifica situações de conflito armado, fornece informações sobre as partes desses conflitos e o direito internacional aplicável. O objetivo é fornecer uma classificação independente e imparcial das situações de conflito armado no mundo, com base em informações de código aberto em um formato acessível a um amplo público, incluindo não advogados e não especialistas em direito internacional humanitário. $O$ projeto RULAC é uma fonte de referência jurídica para um amplo público interessado em questões relacionadas à classificação de conflitos armados sob o direito humanitário internacional, incluindo especialistas em direito, oficiais do governo, formuladores de políticas em organizações ou ONGs internacionais, profissionais humanitários e jornalistas que trabalham em questões humanitárias ou questões de segurança e acadêmicas.
} 


\section{Humanos e}

Democracia

vertentes do Direito ao longo do tempo, constituiu-se a ordem; e a evolução da consciência jurídica universal foi finalmente possível, protegendo-nos de nós mesmos.

Considerando que o Estado foi criado para o ser humano, em seu intuito inerente de proteção, para o mesmo objetivo existe o Direito, em sua forma mais pura, como ferramenta para proteger seres humanos de outros seres humanos e regular tudo que existe, inclusive a guerra. A justificativa para tal entendimento baseia-se na compreensão kantiana do ser humano como um fim em si mesmo e não como um mero instrumento; ideal este redimensionado e atualizado por Cançado Trindade ao pôr a ordem internacional por inteiro à mercê da proteção humana, na medida em que ressalta ao longo de suas obras a necessidade de assegurar a proteção eficaz do ser humano como centro do Sistema de Proteção: "O Direito Internacional não se reduz, em absoluto, a um instrumental a serviço do poder; seu destinatário final é o ser humano, devendo atender às suas necessidades (inclusive as de proteção)" (CANÇADO TRINDADE, 2006, p. 471).

Nesse sentido, compreende-se a convergência das vertentes como fenômeno jurídico essencial para a eficácia da proteção do ser humano, de modo a não permitir que lacunas normativas das vertentes isoladas determinem os destinos daqueles que da norma se servirem. Assim entendido, é mais do que nunca necessário analisar o Direito Internacional Humanitário como vertente da Proteção Internacional da Pessoa Humana que, por si só e isoladamente, não é capaz de representar esse escudo da forma mais adequada.

Dessa forma, considerando o permanente estado de belicosidade mundial, característica intrínseca à nossa natureza - trazendo consigo graves violações de direitos humanos - não há momento mais preciso do que este para trazer o tema à discussão. Nesse caso, o mais novo Estado Ocupante responsável pela proteção dos direitos humanos do indivíduo falha em garanti-los por meio da ação ou da omissão imperiosa, impondo ou oportunizando graves violações do DIH; causando, por consequência, outros resultados desastrosos sob a égide do Direito Internacional dos Refugiados e dos Direitos Internacional dos Direitos Humanos.

Ressalta-se que o Direito Internacional dos Direitos Humanos - apesar de ter se desenvolvido com inclinações claras para somente ser aplicado em tempos de paz, enquanto o Direito Internacional Humanitário se voltaria aos tempos de guerra - também tem se mostrado aplicável no que respeita às violações de direitos básicos e as suas respectivas investigações e persecuções por parte do Estado no qual se desenvolve o conflito armado (MURRAY, 2016).

Ou seja, a vertente do DIDH foi estabelecida com a finalidade de proteger os indivíduos das violações perpetradas pelo seu Estado de origem por agentes estatais, representantes do poder uno que daquele se origina, por meio de uma relação vertical de aplicabilidade. Desse entendimento podemos retirar algumas premissas próprias dos direitos humanos, como a ideia de que a relação entre o Estado e o indivíduo deve ser harmoniosa e benéfica, não só no que diz respeito às obrigações negativas, mas também no apoio ao desenvolvimento do potencial individual daqueles mantidos sob a jurisdição estatal (PROVOST, 2004).

Além disso, o Direito Internacional dos Direitos Humanos, apesar de sua aplicabilidade irrestrita no que respeita às circunstâncias - pois não sei limita, como o Direito Internacional Humanitário, a conflitos armados, ou a situações de deslocamento forçado, como o Direito Internacional dos Refugiados - restringe-se, em certa medida, aos âmbitos regionais de seus sistemas de fiscalização, monitoramento e sanção, além do próprio Estado. Diferentemente, 
o Direito Internacional Humanitário é estabelecido por meio do dimensionamento horizontal de sua eficácia, ao estabelecer obrigações mútuas entre Estados, ou mesmo entre grupos armados não estatais em relação às normas humanitárias.

Por conseguinte, destaca-se o tema a ser investigado, pois busca expor soluções válidas para contribuir com os debates em virtude da interferência do Direito Internacional dos Direitos Humanos na área de jurisdição do Direito Internacional Humanitário, com o simples objetivo de complementar harmoniosamente a Proteção Internacional da Pessoa Humana. $\mathrm{Na}$ ainda obscura área de transição entre os dois campos, é necessário consolidar os pontos de convergência e divergência, para que tais normativas não sejam utilizadas para fins obscuros.

Entre as disposições globais aplicáveis, é necessário destacar a Declaration of Minimum Humanitarian Standards, que determina os padrões humanitários mínimos aplicáveis a todas as situações - incluindo distúrbios internos, tensões locais, ataques à ordem pública - e a todas as pessoas - incluindo grupos e autoridades, independentemente de seu estatuto jurídico ou de qualquer outro aspecto característico - artigos 10 e 2ㅇ do Document No. 55, UN, Minimum Humanitarian Standards (UNITED NATIONS, 1990). Além disso, em caso de conflito armado, as regras do DIH serão aplicadas a todo o território nacional das partes envolvidas no conflito e não se limitarão ao campo de batalha.

\subsection{A Letalidade da Guerra e a Paz como Condição Primordial para a Proteção dos Direitos Humanos}

Um Conflito Armado Internacional (CAI) nada mais é do que a concepção tradicional de guerra, entendida por milhares de anos como o destino da humanidade, derivada do desejo inato de destruição, dominação e poder. Para ser classificado como tal, o CAI deve representar a situação de violência em que dois ou mais Estados recorrem à força armada. Tanto os motivos do conflito quanto a intensidade não são considerados para a classificação, bastando envolver dois ou mais Estados Nacionais.

Para Conflitos Armados Internacionais aplicam-se todas as Convenções de Genebra de 1949, o Protocolo Adicional I e o DIH Costumeiro. Além disso, a declaração de guerra dos Estados-Partes não é necessária; por si só a realidade do confronto ou da invasão é suficiente. Outro ponto importante é que a duração do conflito ou variações na intensidade da violência armada, como massacres, ou períodos de suspensão dos movimentos militares para fins humanitários, são desconsideradas para a sua classificação.

Assim, consideram-se salutares os apontamentos de Swinarski (1996, p. 12), no que concerne à importância do Direito Internacional Humanitário, tido como "direito de guerra", quando se determinou na Conferência de Direitos Humanos, convocada pelas Nações Unidas em Teerã, em 1968, na resolução XXIII, a essencialidade da proteção em tempos de guerra, como regras tidas como o mínimo necessário para a manutenção da dignidade. Além disso, o respeito à paz como "condição primordial para o pleno respeito aos direitos humanos, sendo a guerra a negação desse direito". No mesmo sentido vai o pensamento de Coupland, ao propor que "a predisposição dos humanos para fabricar e usar armas, a humanidade e o direito internacional andam de mãos dadas como necessidades universais da existência humana" (COUPLAND, 2001, p. 989).

As situações de violência armada podem atingir certos limiares ou marcos preestabelecidos, os quais funcionam como balizas para impedir a fragmentação das normas humani- 
tárias mediante a sua banalização. Os chamados thresholds do Direito Internacional Humanitário indicam as fronteiras entre a aplicação da vertente de DIH e de DIDH por meio, por exemplo, da diferenciação entre a composição de motins, levantes, rebeliões e outras formas de tensões ou distúrbios internos e a conformação de um conflito armado não internacional.

A extensão de seus impactos para a comunidade e a ordem social do território no qual se desenvolve a situação de violência armada, assim como a intensidade dos confrontos armados também compõem critérios para essa caracterização. Nesse sentido, insta salientar que, nos casos em que as normas humanitárias não sejam aplicadas, outras formas de proteção deverão ser estabelecidas, como as disposições do Direito Internacional dos Direitos Humanos e o Direito interno do Estado em questão.

Portanto, não se trata de fazer da guerra uma situação humana, e, do mesmo modo, não se pretende que suas regras de caráter humanitário que regem a condução das hostilidades sejam utilizadas pelos beligerantes como um argumento para considerar sua causa como sendo uma guerra justa, mas se propõe a impedir que as partes em um conflito armado atuem com uma crueldade cega e implacável, e proporcionar a proteção fundamental que os mais diretamente afetados pelo conflito necessitam, sem que a guerra de seguir sendo o que sempre foi: um fenômeno aterrador (GUERRA, 2021, p. 511).

Nesse âmbito, concentram-se algumas das principais divergências entre as vertentes. Como exemplo pode-se citar o uso da força letal, que no DIH figura como princípio basilar da própria existência do conflito armado e, consequentemente, do Direito Internacional Humanitário - desde que necessário à consecução dos objetivos militares, pois a guerra em si consiste em sobrepor as suas forças militares às do inimigo. Por outro lado, essa mesma força letal, para o DIDH e os ordenamentos nacionais, é a ultima ratio (BRENNEKE, 2020).

A esse respeito, vale ressaltar que adotamos a linha de complementaridade para a máxima proteção possível diante dos horrores da guerra. Além disso, é importante considerar a harmonia entre ambas as vertentes e aplicar as disposições com precaução, de modo que sejam efetivas e positivas para o objeto de proteção para o qual foi idealizada a norma (PROVOST, 2004).

Ao concluirmos por ora este ponto de convergência particularmente interessante entre as duas áreas do Direito Internacional, tangenciamos a dignidade humana:

O Direito Internacional Humanitário tem a finalidade de amenizar o sofrimento alheio, buscando, ainda que em uma situação catastrófica e pavorosa, o mínimo que se possa preservar em uma pessoa: a sua dignidade. (...) O princípio da humanidade se apresenta como "coluna vertebral" do DIH, estabelece que em qualquer situação, ainda que degradante, deva-se buscar conservar a dignidade da pessoa humana (GUERRA, 2021, p. 515).

O princípio da humanidade possui, para o Direito Internacional Humanitário, conteúdo de valor equivalente ao que o princípio da dignidade da pessoa humana representa para o Direito Internacional dos Direitos Humanos. O conceito de "humanitarismo" ou a definição do que é "humanitário" deriva de uma dedicação intrínseca ao alívio do sofrimento humano e à proteção do bem-estar, da dignidade e da vida de outros seres humanos, particularmente em relação àqueles que se encontram em um estado de vulnerabilidade. Qualquer outro princípio alinhado à ideia de humanitarismo é proveniente deste. 


\section{AS ANTINOMIAS EM CAMPO NA COMPLEXA RELAÇÃO ESTADO OCUPANTE-POPULAÇÃO OCUPADA}

Quando o Direito Internacional entra em campo, principalmente considerando um cenário de conflito armado ou, em outras palavras, um cenário de colapso do Estado de Direito, às vezes é difícil observar suas consequências práticas ou como essa norma se aplicará quando for necessário invocá-la. A verdade é que a abstração e a generalidade da norma dificilmente atenderão aos desafios da realidade prática. Podemos observar, no entanto, a seguinte dinâmica ocorrendo: marcos jurídicos, égide, escudos, guarda-chuvas normativos imaginários que se abrem sobre os objetos jurídicos concernentes para protegê-los e sobre estes pairam a classificação "Direito Internacional Humanitário" ou "Direito Internacional dos Direitos Humanos".

Teorizações à parte, a premissa sustenta-se na medida em que é necessário equilibrar a relação jurídica desproporcionalmente inclinada aos anseios do Estado Ocupante, quando vislumbramos tamanha vulnerabilidade deliberadamente reservada à população do Estado ocupado. Conforme descrito por Sassòli (2019, p. 303): "Such expanded protection is justified because such civilians are living in their territory and through no choice of their own come into contact with the enemy who gained territorial control over the place where they live". ${ }^{4}$

A esse Estado Ocupante são conferidas as obrigações e deveres, antes destinadas ao Estado Ocupado, quanto à proteção dos direitos humanos da população. Ao mesmo tempo, governam as leis imperativas do Direito Internacional dos Conflitos Armados, independentemente de haver resistência à ocupação (CRAWFORD; PERT, 2015).

Caso haja resistência, acentuam-se os conflitos de normas, pois concomitantemente o poder ocupante deve proteger os direitos humanos da população ocupada e fazer o necessário e suficiente - dentro do princípio da necessidade militar do DIH - para atingir seus objetivos militares. Também é relevante destacar que a falta de resistência não significa consentimento para nenhum meio legal.

Ademais, é interessante perceber que as ocupações militares, na condição de modalidades à parte em meio ao DIH, estabeleceram um conjunto de normas em torno destas que dizem respeito às obrigações que o Estado Ocupante possui, mesmo após o fim da ocupação. Isto porque o Estado Ocupante toma o lugar do Estado ocupado, derivando dele as suas obrigações e deveres estatais para com os cidadãos.

Independentemente disso, os deveres de um Estado Ocupante de acordo com o Direito Internacional incluem o reconhecimento de que, mesmo enquanto uma ocupação militar está em curso e o exercício da soberania do Estado Ocupado está suspenso, o Estado Ocupado permanece reconhecido como Estado Nacional sob a égide do Direito Internacional e mantém seus direitos de autodeterminação. A integridade territorial e a independência política devem estar em primeiro lugar entre esses direitos, conforme enfatizado no artigo 20 (4) da Carta das Nações Unidas (BROWN, 2004).

\footnotetext{
4 Essa proteção ampliada é justificada porque tais civis estão vivendo em seu território e sem escolha própria entram em contato com o inimigo, que ganhou o controle territorial sobre o local onde vivem (tradução nossa).
} 
O aludido conjunto de regras - Laws of occupation ou law of belligerent occupation (SASSÒLI, 2019) - encontra-se resumido no artigo 60 da IV Convenção de Genebra de 1949 e se refere: primeiramente, ao respeito pelas Convenções de Genebra e seus Protocolos e à proteção conferida às pessoas protegidas - e nesses termos é essencial ressaltar a responsabilidade prevista no artigo 29 da IV Convenção de Genebra de 1949, a qual trata da responsabilidade do Estado pelas atitudes de seus agentes contra as pessoas protegidas, entendimento confirmado pela doutrina vigente (TORROJA, 2017).

Claramente, então, em relação à população ocupada, particularmente os civis - aqueles que recebem o status de civis e proteção relacionada ao atender aos critérios de "não participar das hostilidades" - prescrevem normas de salvaguarda mais completas que não exigem responsabilidades com a contraparte. Para manter seu status sob o DIH quanto à Potência Ocupante, os civis são obrigados a não resistir violentamente ou usar qualquer meio violento contra as Forças Armadas Ocupantes, mesmo agindo em vontade libertadora. Ao contradizer esta disposição, eles podem ser punidos pela legislação introduzida pela Potência Ocupante sem perder seu status (ICRC, 2009). Como pode ser constatado, a configuração do status localiza-se em âmbito pessoal:

The status, rights, and protections of persons outside the conduct of hostilities do not depend on their qualification as civilians but on the precise personal scope of application of the provisions conferring the relevant status, rights, and protections ${ }^{5}$ (e.g., Arts $4 \mathrm{GC} \mathrm{III,}$ 4 GC IV, 3 GC I-IV, 75 AP I, 4 to 6 AP II) (ICRC, 2009).

Ao contrário, a Potência Ocupante deve respeitar o conjunto de Laws of Occupation, que pretende estabelecer que a vida permaneça o mais normal possível, no respeito ao Direito Internacional dos Direitos Humanos que rege a relação vertical do Estado de fato sobre seus cidadãos de fato. Desse modo, o Estado de Direito local permanece eficiente, ${ }^{6}$ além de outras tipologias de normas relacionadas à conservação do patrimônio público e privado, proibição de deslocamento ou deportação da população ocupada, prestação de segurança, higiene, saúde pública, alimentação e insumos médicos (ICRC, 2009).

\subsection{A Ocupação Militar Segundo o Direito Internacional Humanitário}

Para classificar um CAI em ocupação militar, alguns critérios devem ser atendidos, conforme explicitado pelo sistema Rulac, utilizado como banco de dados para esta pesquisa. Segundo essa definição, as ocupações militares tornaram-se uma modalidade de destaque, devido à identificação de uma série de características presentes em alguns Conflitos Armados Internacionais, o que lhes conferiu um modus operandi diferenciado dos demais CAls existentes. A acentuação de sua ocorrência também determinou a importância de um aprofundamento no seu estudo, bem como no aprimoramento das normas específicas das ocupações militares - chamadas Laws of occupation.

O status, direitos e proteção de pessoas fora da conduta de hostilidades não dependem de sua qualificação como civis, mas do escopo pessoal preciso de aplicação das disposições que conferem o status, direitos e proteções relevantes (tradução nossa).

6 Quanto ao artigo 43 dos regulamentos relativos às Leis e Costumes de Guerra em campanha, em terra. 
A descrição mais próxima de um conceito para o instituto encontra-se no artigo 42 do Regulamento de Haia contido na IV Convenção de Respeito às Leis e Costumes da Guerra Terrestre, de 1907, que determina que para que um território seja considerado ocupado, ou seja, para que seja definida a existência legal de uma ocupação militar, nos termos do Direito Internacional Humanitário, o território: "está efetivamente sob a autoridade do exército hostil. A ocupação estende-se apenas ao território onde essa autoridade foi estabelecida e pode ser exercida". No mesmo sentido, as Convenções de Genebra afirmam, por meio do artigo 2ㅇ (2), que "The Convention shall also apply to all cases of partial or total occupation of the territory of a High Contracting Party, even if the said occupation meets with no armed resistance"7 (INTERNATIONAL..., 1949, p. 35).

Quanto às ocupações militares, estas se caracterizam por serem tipos de conflitos armados internacionais, que preenchem os elementos definidos como necessários à sua existência, principalmente no que se refere à noção de controle efetivo, consistindo na coexistência de três elementos:

(I) Armed forces of a foreign state are physically present without the consent of the effective local government in place at the time of the invasion. (II) The local sovereign is unable to exercise his authority due to the presence of foreign forces. (III) The occupying forces impose their authority over the territory. Once one of these three criteria is no longer fulfilled, the occupation has ended ${ }^{8}$ (GENEVA, 2021).

O Comitê Internacional da Cruz Vermelha determina que as regras do Direito Internacional Humanitário "become applicable whenever territory comes under the effective control of hostile foreign armed forces, even if the occupation meets no armed resistance and there is no fighting" (ICRC, 2004). O CICV interpreta "Controle" de duas maneiras:

It could be taken to mean that a situation of occupation exists whenever a party to a conflict exercises some level of authority or control within foreign territory. So, for example, advancing troops could be considered bound by the law of occupation already during the invasion phase of hostilities. This is the approach suggested in the ICRC's Commentary to the Fourth Geneva Convention (1958). An alternative and more restrictive approach would be to say that a situation of occupation exists only once a party to a conflict is in a position to exercise sufficient authority over enemy territory to enable it to discharge all of the duties imposed by the law of occupation. This approach is adopted by a number of military manuals ${ }^{10}$ (ICRC, 2004).

\footnotetext{
A Convenção também se aplicará a todos os casos de ocupação parcial ou total do território de uma Alta Parte Contratante, mesmo que a referida ocupação não encontre resistência armada (tradução nossa).

8 (I) Forças armadas de um estado estrangeiro estão fisicamente presentes sem o consentimento do governo local efetivo no local no momento da invasão. (II) O soberano local não pode exercer sua autoridade devido à presença de forças estrangeiras. (III) As forças ocupantes impõem sua autoridade sobre o território. Uma vez que um desses três critérios não seja mais atendido, a ocupação é encerrada (tradução nossa).

9 Tornam-se aplicáveis sempre que o território ficar sob o controle efetivo de forças armadas estrangeiras hostis, mesmo que a ocupação não encontre resistência armada e não haja combates (tradução nossa).

${ }^{10}$ Isso poderia significar que uma situação de ocupação existe sempre que uma parte em um conflito exerce algum nível de autoridade ou controle em território estrangeiro. Assim, por exemplo, o avanço das tropas pode ser considerado vinculado à lei de ocupação já durante a fase de início das hostilidades. Essa é a abordagem sugerida no Comentário do CICV à Quarta Convenção de Genebra (1958). Uma abordagem alternativa e mais restritiva seria dizer que uma situação de ocupação existe apenas quando uma parte em um conflito está em posição de exercer autoridade suficiente sobre o território inimigo para permitir-lhe cumprir todos os deveres impostos pela lei de ocupação. Essa abordagem é adotada por vários manuais militares (tradução nossa).
} 
Cabe diferir também, seguindo o presente raciocínio, os institutos Invasão e Ocupação, buscando compreender quando uma invasão se torna uma ocupação de fato, nos termos da decisão conferida ao caso List, durante o Hostages Trial do Tribunal Militar de Nuremberg, em 1948:

At the outset, we desire to point out that International Law makes no distinction between a lawful and an unlawful occupant in dealing with the respective duties of occupant and population in occupied territory. There is no reciprocal connection between the manner of the military occupation of territory and the rights and duties of the occupant and population to each other after the relationship has indeed been established. Whether the invasion was lawful or criminal is not an important factor in the consideration of this subject $^{11}$ (UNITED..., 1949, p. 59).

Isso não significa que todos os atos perpetrados pela Potência Ocupante contra a População Ocupada ou sua propriedade seriam considerados crimes, nem que todos os atos praticados pela População Ocupada contra a Potência Ocupante em termos de resistência armada seriam considerados um ato próprio de defesa. Além disso, as semelhanças encontradas e a própria falta de clareza quanto aos limites jurisdicionais de cada área - DIH e DIDH - têm sido utilizadas como argumento para a redução da proteção legal em conflitos armados (MELZER, 2019).

É valioso considerar também o fato de que, historicamente, o reposicionamento das normas do DIH relativas aos freedom fighters dos movimentos de libertação nacional, nos Conflitos Armados Internacionais - ou, em outras palavras, dos povos que "lutam contra a dominação colonial e estrangeira, contra a ocupação ou contra regimes racistas no exercício do seu direito à autodeterminação "(artigo 10 (4) do Protocolo I), conforme consagrado na Carta das Nações Unidas - melhorou a sua proteção e salvaguarda da dignidade, em relação a esta notavelmente ameaçada categoria de pessoas, pois, assim, podem receber o status de prisioneiro de guerra (SASSÒLI, 2019).

Existem, no entanto, normas de conduta da Potência Ocupante que devem ser observadas de acordo com o Direito Internacional. Outro ponto essencial da discussão aqui apresentada é: Qual tribunal seria competente nesses casos para julgar esses crimes, considerando a rejeição e inadequação deliberada de um tribunal nacional recentemente estabelecido pelo poder ocupante para se julgar seus próprios crimes de guerra. Em que ponto esses casos deixam de ser uma questão de Direito Internacional Humanitário para se tornarem uma questão de Direito Internacional dos Direitos Humanos e como garantir que a proteção humana não seja ameaçada, no que diz respeito ao choque com a lei marcial?

De acordo com o Direito Internacional, qualquer Estado pode fazer cumprir o Direito Internacional Humanitário por meio de seus sistemas jurídicos nacionais e seus mecanismos. 0 Conselho de Segurança da ONU também tem autoridade para tomar todas as medidas necessárias para fazer cumprir o Direito Internacional Humanitário, incluindo obrigar os Estados a cumprir suas obrigações e deveres de estabelecer tribunais para investigar as violações.

\footnotetext{
${ }^{11}$ Em primeiro lugar, desejamos salientar que o Direito Internacional não faz distinção entre um ocupante legal e um ocupante ilegal ao lidar com os respectivos deveres de ocupante e população em território ocupado. Não há conexão recíproca entre a forma de ocupação militar do território e os direitos e deveres do ocupante e da população um para com o outro depois que a relação foi efetivamente estabelecida. Se a invasão foi legal ou criminosa não é um fator importante na consideração deste assunto (tradução nossa).
} 


\subsection{A Ocupação Militar Segundo o Direito Internacional dos Direitos Humanos}

Por sua vez, uma "Ocupação Militar" pode ser descrita como "a transitional period following invasion and preceding the agreement on the cessation of the hostilities", 12 conforme define a jurisprudência no caso n.. IT-98-34-T Prosecutor v. Naletilic' et al. (DARCY, 2014) e é a situação fática que mais aproxima as vertentes de DIH e DIDH. Pode-se, assim, afirmar que o poder ocupante, ao tomar parcialmente ou integralmente o território do poder protetor, substitui o governo anteriormente estabelecido pelo seu novo Estado. 0 artigo 42 dos Regulamentos de Haia de 1907 afirma: "Territory is considered occupied under International Law when it is actually placed under the authority of the hostile army," e tal ocupação "extends only to the territory where such authority has been established and can be exercised."13

A este respeito, o Protocolo Adicional I, sobre a proteção da população civil em Conflitos Armados Internacionais, dos quais a ocupação militar é uma modalidade, demonstra a vinculação aos Direitos Humanos ao dispor no artigo 72 (Campo de aplicação):

The provisions of this Section are additional to the rules concerning humanitarian protection of civilians and civilian objects in the power of a Party to the conflict contained in the Fourth Convention, particularly Parts I and III thereof, as well as to other applicable rules of International Law relating to the protection of fundamental human rights during international armed conflict ${ }^{14}$ (INTERNATIONAL..., 1977, p. 279).

Desse modo, a interpretação estritamente territorial, dentro dos limites geográficos do Estado, deve ser estendida para além da jurisdição inicialmente prevista, de modo que o Estado seja responsável pelas violações cometidas além de suas fronteiras, inclusive em relação a minorias e pessoas de outras nacionalidades (MARTIN, F. F. et al., 2006). As disposições relativas à assistência coletiva às necessidades básicas também estão incluídas como parte da proteção contra violações dos direitos humanos e do DIH prevista na IV Convenção de Genebra de 1949.

As operações militares das forças governamentais organizadas são restringidas pelo Direito Internacional e pelo Direito Internacional Humanitário para preservar a vida civil na medida do possível em conflitos armados e para estabilizar a sociedade civil uma vez que as hostilidades tenham diminuído. É essencial que sejam desenvolvidos estudos significativos para alcançar um equilíbrio entre processar operações militares e ao mesmo tempo respeitar os direitos humanos, proteger os não combatentes e preservar o Estado de Direito.

Vários fatores-chave emergiram da análise e têm aplicação direta em regiões do mundo em que os Estados-nação estão envolvidos em conflitos militares e lutando para fortalecer o Estado de Direito, alcançar estabilidade sociopolítica e responder às violações dos direitos humanos como consequência de ações beligerantes.

\footnotetext{
12 Um período de transição após a invasão e precedendo o acordo sobre a cessação das hostilidades (tradução nossa).

${ }^{13} \mathrm{O}$ território é considerado ocupado pelo Direito Internacional quando está efetivamente colocado sob a autoridade do exército hostil", e aquela ocupação "se estende apenas ao território onde essa autoridade foi estabelecida e pode ser exercida (tradução nossa).

${ }^{14}$ As disposições desta Seção são adicionais às regras relativas à proteção humanitária de civis e objetos civis em poder de uma Parte no conflito contidas na Quarta Convenção, particularmente nas Partes I e III dela, bem como a outras regras aplicáveis do Direito Internacional relacionadas à proteção dos direitos humanos fundamentais durante o conflito armado internacional (tradução nossa).
} 


\section{A COMPLEMENTARIDADE DOS SISTEMAS NORMATIVOS E A NECESSÁRIA SUBORDINAÇÃO DO DIREITO INTERNACIONAL HUMANITÁRIO}

Algumas considerações sobre o Direito Internacional Humanitário e a proteção da pessoa humana são notórias, dada sua natureza peculiar a outros aspectos do Direito em geral, mas comuns aos aspectos da proteção internacional da pessoa humana. Daí sua localização sistemática juntamente ao Direito Internacional dos Refugiados e ao Direito Internacional dos Direitos Humanos. O DIH, como já vimos, possui uma série de características, objetivos e princípios próprios, que devem ser compreendidos por meio de interpretação sistemática.

De nada, assim, adiantaria que o DIH se unisse às demais vertentes em uma classificação apenas, como defende a doutrina integracionista, ou que se isolasse dos demais núcleos de proteção, como advoga a doutrina separatista, mas sim, respeitando as suas fundamentações de todo diferentes, seus princípios próprios e objetivos diversos, o ideal permanecesse sendo a sua complementação mútua ao mesmo tempo que sua independência floresce no campo normativo e jurisprudencial.

Devemos também compreender que na colisão de princípios ou de normas das duas vertentes, devem ser analisados contexto a contexto e norma a norma, isto é, em um caso concreto, um sistema normativo não pode se sobrepor a outro, pois estes se complementam, na medida em que derivam do mesmo valor original, qual seja, a proteção do ser humano em suas considerações básicas de humanidade (CANÇADO TRINDADE, 2006) ou razões de humanidade (COOPER; LARSEN; NYSTUEN, 2013).

Assim, uma norma ou princípio é considerado mais adequado àquele contexto e por isto deve ser aplicado naquele momento em específico e naquela situação, ou mesmo pode-se reconhecer a aplicação simultânea. Isto é particularmente verdadeiro para casos não previstos em tratados, ou nos costumes do Direito Internacional Humanitário, quando é necessário recorrer à Cláusula Martens, conforme estabelecido no artigo 10 (4) do Protocolo Adicional I às Convenções de Genebra.

Segundo Melzer (2019), quando do encontro normativo das disposições concernentes às duas áreas, temos encontrado argumentações falaciosas, no sentido de ampliar os limites para o uso da violência, utilizando o DIH e o seu princípio da necessidade militar - abandonando-se, cada vez mais, o princípio da humanidade - enquanto disposições de DIDH são destinadas a prisioneiros, derrogando-se seus direitos, na medida em que assim é possível para essa vertente, enquanto o instituto de prisioneiro de guerra é ignorado.

International human rights law applies at all times to all peoples during all occasions, including during armed conflict and military occupation. Notwithstanding their distinct purposes, international human rights law is to be read as being complementary to international humanitarian law in situations of occupation, thereby satisfying the purpose of both of these bodies of law to provide broad protection of rights to everyone, including to protected peoples under occupation. As such, the full panoply of social, economic, 
cultural, political and civil rights enshrined in international human rights law is available to peoples living under occupation to protect their sovereignty over their natural wealth (HUMAN RIGHTS COUNCIL, 2019). ${ }^{15}$

A esse respeito, a aplicabilidade ou a inaplicabilidade das regras do DIDH em contextos de conflito armado não são mais discutidas; no entanto uma série de dúvidas surge sobre como essa aplicação ocorrerá. Outro ponto que devemos destacar diz respeito à maior força sancionadora do DIDH quando comparada ao enforcement produzido pelo DIH, visto que aquele se fragmenta por meio de uma série de órgãos jurisdicionais que podem ser invocados ao abrigo da lei. Finalmente, deve-se notar que o Direito Internacional Humanitário também é algumas vezes referido na doutrina como "International Law for Human Rights in Armed Conflict" (FORSYTHE, 2012, p. 57) - demonstrando a inter-relação limítrofe entre ambos.

Com base nos estudos aqui apresentados, verifica-se que é possível afirmar as convergências entre os dois sistemas de proteção, na medida em que, para cada corpo de leis, tendências semelhantes de violações são observadas, específicas para cada cenário. Percebe-se também que as violações tendem a ser classificadas por intermédio do seu sujeito destinatário enquanto pessoa protegida, seja quando se considera categorias de pessoas vulneráveis - como era nos primórdios do desenvolvimento do DIDH - seja quando se deriva a ideia de direitos mínimos para todos os seres humanos.

Além disso, a identificação das principais infrações em cada corpo de leis é um dos primeiros passos para que as respectivas punições sejam determinadas e, assim, garantir um maior nível de eficácia das normas, por meio da análise das antinomias. A seguir, será apresentado o caso concreto em análise, o Conflito Armado Internacional de modalidade Ocupação Militar entre Palestina e Israel, a fim de analisar os pontos de convergência entre o DIH e o DIDH no que diz respeito às violações.

O estudo do referido caso é particularmente interessante, porque contém em si uma ampla gama de antinomias jurídicas a serem resolvidas na circunstância mais grave para a vida e a dignidade humanas: o conflito armado. Tais antinomias, se não resolvidas da forma mais adequada, acabam gerando graves violações aos direitos humanos, utilizando, para os já mencionados escusos fins, os canais legais estabelecidos, como ocorre atualmente na recente retomada de confrontos entre Palestina e Israel. Diante do exposto, não temos escolha a não ser investigar a demanda atual, com o propósito primordial de prevenir a deterioração da Proteção Internacional da Pessoa Humana, evitando sua ruína pelos próprios fundamentos.

\footnotetext{
${ }^{15}$ O Direito Internacional dos Direitos Humanos se aplica sempre a todos os povos, em todas as ocasiões, inclusive durante conflitos armados e ocupações militares. Não obstante seus objetivos distintos, o Direito Internacional dos Direitos Humanos deve ser lido como complementar ao Direito Internacional Humanitário em situações de ocupação, satisfazendo assim o propósito de ambos os corpos de lei de fornecer ampla proteção de direitos a todos, inclusive aos povos protegidos sob ocupação. Como tal, toda a panóplia de direitos sociais, econômicos, culturais, políticos e civis consagrados no Direito Internacional dos Direitos Humanos está disponível para os povos que vivem sob ocupação para proteger sua soberania sobre sua riqueza natural (tradução nossa).
} 


\section{Democracia}

\section{CONFLITO ISRAEL-PALESTINA E OS CONFRONTOS EM 2021}

Israel ocupa o território da Palestina desde o fim da Guerra dos 6 dias em 1967, sendo internacionalmente reconhecida como Poder Ocupante ou Potência Ocupante da Cisjordânia, incluindo Jerusalém Oriental e a Faixa de Gaza.

Em relação à Ocupação Militar da Palestina por Israel, vislumbra-se um conflito histórico, marcado por uma divisão política exterior ao conhecimento do conflito religioso de ordem interna entre os dois povos, de modo que Israel ocupa a área que fora destinada ao convívio pacífico entre ambos (FERRER, 2018). Desde então, uma série de violências foi perpetrada à dignidade humana dos palestinos nas áreas ocupadas (Faixa de Gaza e as áreas de West Bank e East Jerusalem). Para o próximo quadro foram utilizados os relatórios: Armed Conflict In Israel-Palestine (GENEVA ACADEMY, 2021), o World Report 2019: events of 2018 (HRW) e o Global Humanitarian Overview 2019 (OCHA).

Figura 1 - Quadro representativo dos estudos de eficácia do Direito de Genebra em relação às pessoas protegidas na Ocupação Militar da Palestina por Israel (Conflito Armado Internacional), bem como em relação ao acervo de leis do DIDH

\begin{tabular}{|l|l|l|}
\hline OCUPAÇÃO MILITAR DA PALESTINA POR ISRAEL \\
\hline $\begin{array}{c}\text { PRINCIPAIS PESSOAS } \\
\text { PROTEGIDAS AFETADAS }\end{array}$ & PRINCIPAIS VIOLAÇÕES DE DIH & PRINCIPAIS VIOLAÇÕES DE DIDH \\
\hline $\begin{array}{c}\text { Feridos e doentes em } \\
\text { campanha, forças navais } \\
\text { e náufragos }\end{array}$ & $\begin{array}{l}\text { Restrição aos cuidados médicos } \\
\text { e tratamento dos feridos; am- } \\
\text { putações por falta de tratamento } \\
\text { médico das lesões; }\end{array}$ & $\begin{array}{l}\text { Toda pessoa tem direito ao respeito } \\
\text { por sua integridade física, mental e } \\
\text { moral; }\end{array}$ \\
\hline $\begin{array}{l}\text { Prisioneiros de guerra e } \\
\text { detidos }\end{array}$ & Prisão arbitrária; maus-tratos; & $\begin{array}{l}\text { Ninguém será sujeito à detenção } \\
\text { ou ao encarceramento arbitrário; } \\
\text { Direito a tratamento humanizado. } \\
\text { Punição ou tratamento cruel, desu- } \\
\text { mano ou degradante; Dignidade de } \\
\text { todas as pessoas privadas de liber- } \\
\text { dade; }\end{array}$ \\
\hline Civis & $\begin{array}{l}\text { Civis considerados alvos; maus-tra- } \\
\text { tos; restrição de bens essenciais à } \\
\text { sua sobrevivência; restrição de elet- } \\
\text { ricidade, alimentação, água, edu- } \\
\text { cação, assistência médica; punições } \\
\text { coletivas. }\end{array}$ & $\begin{array}{l}\text { Ninguém será arbitrariamente priva- } \\
\text { do de sua vida. Toda pessoa tem } \\
\text { direito a um nível de vida adequado } \\
\text { à sua saúde e bem-estar e ao de sua } \\
\text { família, incluindo alimentação, vesti- } \\
\text { menta, moradia, assistência médica } \\
\text { e serviços sociais necessários. A } \\
\text { punição não se estenderá a outra } \\
\text { pessoa que não o criminoso. }\end{array}$ \\
\hline
\end{tabular}

Fonte: Os autores. Adaptado de GENEVA ACADEMY (2021); HRW (2019); OCHA (2019).

Resta válido apontar as disposições declaradas no Relatório do Conselho de Direitos Humanos sobre a high-level fact-finding mission to Beit Hanoun estabelecida sob a resolução do Conselho S-3/1, A/HRC/9/26, em 10 de setembro de 2008: 
Human rights law is also applicable in armed conflict and occupation. The mission considers that this reckless disregard for civilian life also constitutes a violation of the right to life as set out in article 6 of the International Covenant on Civil and Political Rights to which Israel is a party. The right to life includes the negative obligation to respect life and the positive obligation to protect life. The Human Rights Committee has stated that States parties should take measures not only to prevent and punish deprivation by criminal acts but also to prevent arbitrary killing by their own security forces. No exception is made for acts during the war (HUMAN RIGHTS COUNCIL, 2008). ${ }^{16}$

O grupo armado não estatal Hamas tornou-se uma das partes centrais do conflito ao assumir o controle de Gaza em 2006, de modo que Israel a partir desse momento passa a identificar Gaza como um território hostil e a tentar garantir militarmente a ocupação beligerante desse território. Um ponto interessante desta trajetória levou à análise dos protestos palestinos em 2018 que solicitavam visibilidade internacional para as violações ocorridas em Gaza devido aos confrontos:

On 30 March 2018, mass protests began at the Israel-Gaza Strip border. Drawing international condemnation, the use of live ammunition by Israeli armed forces against the protestors led to the highest death toll since the 2014 conflict. In a 25 February 2019 report, a Commission of Inquiry established by the UN Human Rights found that, from 30 March to 31 December 2018, Israeli Security Forces killed 183 Palestinians and injured 9,204 others with live ammunition, by bullet fragmentation, rubber-coated metal bullets or hits from tear gas canisters (according to OCHA estimates, the total number of Palestinians injured during the demonstrations is over 23,000); it also found that one Israeli soldier was killed and four injured at the demonstrations. The Commission concluded that "Israeli soldiers committed violations of international human rights and humanitarian law", and that "[s]ome of those violations may constitute war crimes or crimes against humanity"17 (UNITED..., 2019b).

A análise das violações pelo United Nations Office for the Coordination of Humanitarian Affairs (OCHA) concluiu pela ocorrência de crimes de guerra e violações de direitos humanos, demonstrando a conexão irrestrita entre as violações perpetradas pelos agentes estatais do Estado Ocupante contra a população do Estado Ocupado.

Em 10 de maio de 2021 as tensões entre as forças israelenses e os residentes palestinos se agravam, de modo que o grupo armado não estatal Hamas passa a disparar foguetes, en-

\footnotetext{
${ }^{16}$ A legislação de direitos humanos também é aplicável em conflitos armados e em ocupações. A missão considera que o desrespeito pela vida civil também constitui uma violação do direito à vida, conforme estabelecido no artigo 60 do Pacto Internacional sobre Direitos Civis e Políticos, do qual Israel é parte. O direito à vida inclui a obrigação negativa de respeitar a vida e a obrigação positiva de protegê-la. O Comitê de Direitos Humanos declarou que os Estados-Partes devem tomar medidas não apenas para prevenir e punir a privação por atos criminosos, mas também para prevenir mortes arbitrárias por suas próprias forças de segurança. Nenhuma exceção é feita para atos durante a guerra (tradução nossa).

17 Em 30 de março de 2018, protestos em massa começaram na fronteira entre Israel e a Faixa de Gaza. Atraindo condenação internacional, o uso de munição real pelas Forças Armadas israelenses contra os manifestantes levou ao maior número de mortos desde o conflito de 2014. Em um relatório de 25 de fevereiro de 2019, uma Comissão de Inquérito criada pelos Direitos Humanos da ONU descobriu que, de 30 de março a 31 de dezembro de 2018, as Forças de Segurança de Israel mataram 183 palestinos e feriram 9.204 outros com munição real, por fragmentação de bala, metal revestido de borracha, balas ou disparos de bombas de gás lacrimogêneo (de acordo com estimativas do Ocha, o número total de palestinos feridos durante as manifestações é superior a 23.000); também descobriu que um soldado israelense foi morto e quatro feridos nas manifestações. A Comissão concluiu que "os soldados israelenses cometeram violações dos direitos humanos internacionais e do direito humanitário" e que "algumas dessas violações podem constituir crimes de guerra ou crimes contra a humanidade (tradução nossa).
} 
quanto as forças armadas israelenses, em suposta resposta, promovem uma série de ataques aéreos a regiões urbanas em que se concentram civis palestinos na Faixa de Gaza. Na sequência, considerados unlawful combatants em Gaza, passam também a disparar foguetes contra a área ocupada pelas Forças Armadas de Jerusalém, medida que não era tomada desde os confrontos bélicos de 2014 (GENEVA..., 2021).

Os bombardeios a residentes civis e seus bens permanecem contínuos nas semanas que se seguem, incluindo ataques direcionados à imprensa, particularmente aos escritórios da Associate Press e da Al Jazeera, revelando uma série de violações às normas humanitárias, constituindo, assim, crimes de guerra em relação à proteção dos civis e de seus bens, da imprensa e dos jornalistas diante da IV Convenção de Genebra de 1949 que garante a esses profissionais também o status protetivo de civis:

A person who attempts to obtain or comments on or uses information for the press or for radio or television; any correspondent, reporter, photographer, or cameraman, or his/ her film, radio or television technical assistant, habitually carrying out such activities as his/her main occupation. "Journalists" are civilians and therefore enjoy the protection accorded to civilians unless and for such time as they take a direct part in hostilities ${ }^{18}$ (INTERNATIONAL..., 2021a).

Article 50 - Definition of civilians and civilian population

1. A civilian is any person who does not belong to one of the categories of persons referred to in Article 4 A (1), (2), (3) and (6) of the Third Convention and in Article 43 of this Protocol. In case of doubt whether a person is a civilian, that person shall be considered to be a civilian. 2 . The civilian population comprises all persons who are civilians. 3 . The presence within the civilian population of individuals who do not come within the definition of civilians does not deprive the population of its civilian character (INTERNATIONAL..., 1949). ${ }^{19}$

Ao mesmo conteúdo protetivo de Direito Internacional Humanitário considerado para identificar tais violações, verificamos conteúdo de violação também direcionado ao Direito Internacional dos Direitos Humanos, ao direito de expressão e à liberdade de imprensa. Com relação aos bombardeios civis, abrange-se o direito à vida e o direito à vida digna.

Com a escalada do conflito e a deterioração das mínimas condições de paz e estabilidade que haviam sido construídas com o passar dos anos desde o último grande episódio de enfrentamento, crianças morrem diariamente de ambos os lados, vítimas dos bombardeios, e estruturas de saúde pública e de ajuda humanitária continuam a sofrer danos recorrentes. Conforme descreve o CICV: "Actors on the ground must stop this cycle of violence. The rules

\footnotetext{
${ }^{18}$ Uma pessoa que tenta obter, comentar ou usar informações para a imprensa ou para o rádio ou televisão; qualquer correspondente, repórter, fotógrafo ou cinegrafista, ou seu assistente técnico de cinema, rádio ou televisão, exercendo habitualmente as atividades de sua ocupação principal. Os "jornalistas" são civis e, portanto, desfrutam da proteção concedida aos civis, a menos e durante o tempo em que participem diretamente das hostilidades (tradução nossa).

${ }^{19}$ Artigo 50 - Definição de civis e população civil 1. Um civil é qualquer pessoa que não pertença a uma das categorias de pessoas referidas no Artigo 4으 A (1), (2), (3) e (6) da Terceira Convenção e no Artigo 43 deste Protocolo. Em caso de dúvida se uma pessoa é civil, essa pessoa será considerada civil. 2. A população civil compreende todas as pessoas que são civis. 3. A presença na população civil de indivíduos que não se enquadram na definição de civis não priva a população de seu caráter civil (tradução nossa).
} 
are crystal clear: Civilians must be protected at all times. Sadly, that is not the case today"20 (INTERNATIONAL... 2021b).

Israel é parte da IV Convenção de Genebra de 1949 relativa à proteção dos civis em conflitos armados, porém não ratificou o Protocolo Adicional I de 1977. Por outro lado, a Palestina é parte de todas as Convenções de Genebra e também de seus Protocolos Adicionais. Importante salientar que apesar destes fatos, as normas relativas ao Direito Internacional Humanitário Consuetudinário e ao Direito Internacional dos Direitos Humanos permanecem aplicáveis independentemente do estado de ocupação armada e de forma complementar e possivelmente suplementar ao Direito Internacional Humanitário positivado:

In addition to international humanitarian law, international human rights law continues to apply during times of armed conflict. Israel is a party to both the International Covenant on Civil and Political Rights and the International Covenant on Economic, Social and Cultural Rights. Israel remains bound by its international human rights law obligations in the territory it occupies ${ }^{21}$ (GENEVA..., 2021).

\section{CONSIDERAÇÕES FINAIS}

Conclui-se, primeiramente, que a compartimentalização da Proteção Internacional da Pessoa Humana foi realizada historicamente de modo natural, tendo em vista que o Direito quando restrito a um grupo social ou a uma certa condição ou estado do ser humano nasce para cumprir com determinada necessidade apresentada pela própria humanidade, fazendo jus à proteção específica, pois o rol de direitos das gentes previstos para todos indistintamente não é suficiente para abarcar aquela situação.

Em decorrência deste surgimento espontâneo, seguem as demais consequências teóricas - normativas (nascendo a seu próprio tempo e respeitando o seu desenvolvimento histórico e o conjunto de legislação internacional), principiológicas (pensados os fundamentos mais importantes a serem resguardados pelo órgão responsável por propagá-lo) - e práticas, caracterizadas pela atuação da organização protetora humanitária, sejam qual for a sua natureza (independente, autônoma ou vinculada), com foco na propagação dos princípios humanitários e na disseminação do dever de cumprimento das normas humanitárias. A compreensão da complexa relação que se estabelece entre o os perpetradores e as vítimas, bem como as diversas violações que podem ocorrer em um conflito armado internacional na modalidade de ocupação militar, demonstra as variações que os sistemas de proteção podem produzir e como, na prática, é possível melhorá-los para que todos os vulneráveis permaneçam sob o necessário quadro jurídico de direitos humanos e normas humanitárias.

Analisar os fundamentos do Direito Internacional é estudar a própria História do mundo moderno em construção. Além disso, os pilares da História, da razão e do Estado cruzam-se

\footnotetext{
${ }^{20}$ Os atores locais devem interromper este ciclo de violência. As regras são muito claras: os civis devem ser protegidos em todos os momentos. Infelizmente, não é o caso hoje (tradução nossa).

${ }^{21}$ Além do Direito Internacional Humanitário, o Direito Internacional dos Direitos Humanos continua a ser aplicado em tempos de conflito armado. Israel é parte do Pacto Internacional de Direitos Civis e Políticos e do Pacto Internacional de Direitos Econômicos, Sociais e Culturais. Israel continua vinculado às suas obrigações de Direito Internacional dos direitos humanos no território que ocupa (tradução nossa).
} 
perfeitamente neste tema, considerando, inclusive, as demandas de fronteira. Por fim, entende-se a perfeita sincronia e aderência do presente estudo à linha de pesquisa e à área de estudo devido à sua relevância temática e enquadramento sistemático nos fundamentos do Direito Internacional moderno.

Assim, é claro que violações de direitos humanos podem ocorrer em conflitos armados e não apenas violações do DIH - ou dos chamados crimes de guerra - como se pretendeu demonstrar no decorrer desta pesquisa. Para tanto é necessário, porém, que a interpretação seja sempre realizada de forma teleológica - considerando a finalidade para a qual foi criado o aspecto de proteção - e sistemática - considerando os princípios e demais regras que irradiam e conformam o corpo normativo.

Embora ambas as áreas do Direito façam parte da proteção internacional da pessoa humana e este seja seu objetivo principal, o Direito Internacional Humanitário foi inicialmente criado para conter as atitudes agressivas e comumente desastrosas dos Estados, enquanto o Direito Internacional dos Direitos Humanos foi instituído com base nos direitos subjetivos do ser humano. O DIH foi estabelecido para diminuir os danos ao desejo de autodestruição da humanidade na forma de abstrações políticas supostamente superiores e mais valiosas do que a vida das pessoas que criaram essa ficção jurídica, enquanto o DIDH foi criado com base no princípio de que a vida e dignidade humanas são mais valiosas do que qualquer ficção. Com esta sucinta retomada das origens e fundamentos, podemos entender que os objetivos para os quais cada corpo legislativo foi criado determinam em grande parte qual deles deve prevalecer.

Por último, mas não menos importante, o Direito Internacional Humanitário não pode ser julgado por sua incapacidade de prevenir a ocorrência de conflitos armados ou ocupações militares, uma vez que esta não é sua função. Mesmo que os conflitos armados não existissem e não causassem tanto sofrimento humano como causam, o DIH em si não existiria. Nesse viés, a razão da existência do DIH manifesta-se na resistência aos conflitos armados e sua consequente devoção para mitigar a dor e a destruição.

E logo existe o DIH, intrinsecamente ligado a tal razão de ser, justamente porque urge respeitar e proteger o ser humano, inclusive sua natureza. O DIH existe para nos proteger de nós mesmos e de acordo com nossa dupla natureza. Na mesma medida em que as normas humanitárias protegem as pessoas das consequências das guerras, estas não as impedem de ocorrer, pois simplesmente não é sua função. Se um dia os conflitos armados acabassem e fosse possível viver pela paz, o DIH também morreria, pois se tornaria inútil e o Direito Internacional dos Direitos Humanos poderia, por fim, assumir sua plenitude.

\section{REFERÊNCIAS}

BRENNEKE, M. Lethal Autonomous Weapon Systems and Their Compatibility with International Humanitarian Law: A Primer on the Debate. In: GEIß, R.; GILL, T. D.; KRIEGER, H.; PAULUSSEN, C. Yearbook of International Humanitarian Law 2018. Hague: T.M.C. Asser Press, 2020.

BROWN, B. S. Intervention, self-determination, democracy and the residual responsibilities of the occupying power in Iraq. UC Davis Journal of International Law \& Policy, v. 11, n. 1, p. 23-73, 2004.

CANÇADO TRINDADE, A. A. Desafios e conquistas do direito internacional dos direitos humanos no início do século XXI. In: CURSO DE DIREITO INTERNACIONAL ORGANIZADO PELA COMISSÃO JURÍDICA INTERAMERICANA DA OEA, 33., 2006. Rio de Janeiro: OEA, 2006. 
COOPER, C. G. G.; LARSEN, K. M.; NYSTUEN, G. Searching for a "Principle of Humanity" in International Humanitarian Law. Cambridge: Cambridge University Press, 2013.

COUPLAND, R. Humanity: What is it and how it influences international law? Geneve: RICR, n. 844, p. 969-990, 2001.

CRAWFORD, E.; PERT, A. International Humanitarian Law. Cambridge: Cambridge University Press, 2015.

DARCY, S. Judges, Law and War: the judicial development of International Humanitarian Law. Cambridge: Cambridge University Press, 2014.

FERRER, M. The Armed Conflict in Israel-Palestine. In: The War Report 2017. Geneva: Geneva Academy, 2018.

FORSYTHE, D. P. Human Rights in International Relations. New York: Cambridge University Press, 2012.

GENEVA ACADEMY OF INTERNATIONAL HUMANITARIAN LAW AND HUMAN RIGHTS (GENEVA ACADEMY). Rule of Law in Armed Conflicts Project (RULAC). Geneva: Geneva Academy of International Humanitarian Law and Human Rights, 2021. Disponível em: http://www.rulac.org/

GUERRA, S.; PRONER, C. Direito internacional humanitário e a proteção internacional do indivíduo. Porto Alegre: Sergio Antonio Fabris, 2008.

GUERRA, S. Curso de direitos humanos. 6. ed. São Paulo: Saraiva Educação, 2020.

GUERRA, S. Curso de Direito Internacional Público. 13. ed. São Paulo: Saraiva Educação, 2021.

HAGUE CONVENTION, 6., ANNEX: REGULATIONS CONCERNING THE LAWS AND CUSTOMS OF WAR ON LAND. The Hague, 1907.

HRW. HUMAN RIGHTS COUNCIL. Report of the high-level fact-finding mission to Beit Hanoun established under Council resolution $S-3 / 1, A / H R C / 9 / 26.2008$.

HRW. HUMAN RIGHTS COUNCIL. Human rights situation in Palestine and other occupied Arab territories $A /$ HRC/40/73. 2019. Disponível em: https://www.ohchr.org/EN/pages/home.aspx. Acesso em: 20 abr. 2021.

HRW. HUMAN RIGHTS WATCH. World Report 2019: events of 2018. 2019. Disponível em: https://www.hrw.org/ world-report/2019. Acesso em: 2 jan. 2020.

ICRC. INTERNATIONAL COMMITTEE OF THE RED CROSS. The Geneva Conventions of 12 August 1949. Geneva: ICRC, 1949.

ICRC. INTERNATIONAL COMMITTEE OF THE RED CROSS. Protocol Additional to the Geneva Conventions of 12 august 1949, and relating to the protection of victims of international armed conflicts (Protocol I), of 8 June 1977. Geneva: ICRC, 1977.

ICRC. INTERNATIONAL COMMITTEE OF THE RED CROSS. Interpretive Guidance on the Notion of Direct Participation in Hostilities under International Humanitarian Law. Geneva: ICRC, 2009. Disponível em: http://www.icrc. org. Acesso em: 10 abr. 2021

ICRC. INTERNATIONAL COMMITTEE OF THE RED CROSS. Frequently Asked Questions on the Rules of War. Geneva: ICRC, 2016. Disponível em: https://www.icrc.org/en/document/ihl-rules-of-war-FAQ-Geneva-Conventions Acesso em: 10 abr. 2021

ICRC. INTERNATIONAL COMMITTEE OF THE RED CROSS. How Does Law Protect in War Database. Disponível em: https://casebook.icrc.org/glossary/journalists Acesso em: 10 maio 2021 a.

ICRC. INTERNATIONAL COMMITTEE OF THE RED CROSS. Israel and the occupied territory: Hostilities between Gaza and Israel must stop and much-needed humanitarian activities must start now. Disponível em: https:// www.icrc.org/en/document/israel-and-occupied-territory-hostilities-between-gaza-and-israel-must-stop-and-much-needed Acesso em: 21 maio 2021b.

ICRC. INTERNATIONAL COMMITTEE OF THE RED CROSS. Occupation and international humanitarian law: questions and answers. Geneva: ICRC, 2004.

KALSHOVEN, F.; ZEGVELD, L. Constraints of the waging of war: na introduction to International Humanitarian Law. Geneva: International Committee of the Red Cross, 2001.

MARTIN, F. F. et al. International Human Rights \& Humanitarian Law: treaties, cases \& analysis. New York: Cambridge University Press, 2006.

MELZER, N. International Humanitarian Law: a comprehensive introduction. Geneva: International Committee of the Red Cross, 2019.

MURRAY, D. Practitioners' guide to Human Rights Law in Armed Conflict. Oxford: Oxford University Press; The Royal Institute of International Affairs, 2016.

OBERLEITNER, G. Human Rights in Armed Conflict: law, practice, policy. Cambridge: Cambridge University Press, 2015. 
OCHA. UNITED NATIONS OFFICE FOR THE COORDINATION OF HUMANITARIAN AFFAIRS. Global Humanitarian Overview 2019. 2019a. Disponível em: https://www.unocha.org/global-humanitarian-overview-2019. Acesso em: 3 jan. 2020.

OCHA. UNITED NATIONS OFFICE FOR THE COORDINATION OF HUMANITARIAN AFFAIRS. Report of the detailed findings of the independent international Commission of inquiry on the protests in the Occupied Palestinian Territory. A/HRC/40/CRP.2. 2019b. Disponível em: https://www.ohchr.org/EN/HRBodies/HRC/ColOPT/Pages/Report20180PT.aspx. Acesso em: 21 maio 2021.

OTTO, R. Targeted Killings and International Law. Heidelberg: Springer, 2012.

POPPER, K. R. A lógica da pesquisa científica. São Paulo: Cultrix, 1972.

PROVOST, R. International Human Rights and Humanitarian Law. Cambridge: Cambridge University Press, 2004.

SASSÒLI, M. International Humanitarian Law: rules, controversies, and solutions to problems arising in warfare. Cheltenham: Edward Elgar Publishing Limited, 2019.

SWINARSKI, C. Introdução ao Direito Internacional Humanitário. Brasília: Comitê Internacional da Cruz Vermelha; Instituto Interamericano de Direitos Humanos, 1996.

SWINARSKI, C. O direito internacional humanitário como sistema de proteção internacional da pessoa humana. Revista do Instituto Brasileiro de Direitos Humanos, n. 4, p. 33-48, dez. 2003. ISSN 1677-1419. Disponível em: http://revista.ibdh.org.br/index.php/ibdh/article/view/5. Acesso em: 19 dez. 2021.

TORROJA, H. Public International Law and Human Rights Violations by Private Military and Security Companies. Cham: Springer International Publishing, 2017.

UNITED NATIONS. The United Nations War Crimes Commission: law reports of trials of war criminals. 1949. p. 34-76. v. VIII.

UNITED NATIONS. UN Doc. E/CN.4/Sub.2/1991/55. 1990. Disponível em: http://www.un.org. Acesso em: 20 abr. 2021.

UNITED NATIONS. International Legal Protection of Human Rights in Armed Conflict. 2011. HR/PUB/11/01. Disponível em: https://www.refworld.org/docid/4ee9f8782.html. Acesso em: 5 jan. 2020. 